\title{
OPTIMUM DESIGN OF HYDROSTATIC JOURNAL BEARINGS FOR MINIMUM POWER LOSSES
}

\author{
M.EL-SHERBINY ${ }^{*}$, F.SALEM $^{*}$ and N.EL-HEFNAWY ${ }^{*}$
}

ABSTRACT

This paper presents the results of an optimization study aiming at minimizing the total power losses in hydrostatic journal bearings.

Results illustrating the optimum values of area ratio,pressure ratio, axial land width, and circumferential land width are presented. It is found that some of the design variables tend to settle at extreme values of either upper or lower constraints. It is also found that within the limitations imposed by the governing equations the optimum pressure ratio is 0.5 .

\section{INTRODUCTION}

Because of the growing interest in selection and use of hydrostatic bearings which meets the basic requirements in a wide range of engineering applications [1], standardization of such bearings has been proposed [2]. The standards should enable a designer to select bearings having compact sizes, maximum load capacity, minimum power losses, high stiffness and low tempe-rature rise. Therefore, it is advantageous to optimize bearing dimensions to meet specific rated load capacity while minimizing one or more of the above mentioned objectives. In a previous work [1] an optimization study aiming at maximizing the load carrying capacity of four recess hydrostatic journal bearings was proposed. The present work, however, looks into the optimum design variables in view of minimizing total power losses.

The design of hydrostatic beariny has been studied by a number of investigators [3-9]. The major differences between these investigations lies in the different objectives, governing equations, limit constraints, and optimization techniques. In the present work the Rosenbrock's optimization method [10] is used.

*Associate Profs., Dept. of Mech. Design, Cairo University, Cairo, Egypt. 


\section{FORMULATION OF THE PROBIEM.}

objective inction

The present objective function is the total amount of power consumed by the bearing

where

$$
W_{T}=W_{P}+W_{L}+W_{R}
$$

$$
\begin{aligned}
& W_{p}=\frac{\pi D}{6 b} \beta \frac{p_{s}^{2} c^{3}}{\mu} \\
& W_{L}=[R(I-2 b) a+2 \pi D b]\left[\pi D N_{S}\right]^{2} \frac{\mu}{C} \\
& W_{R}=E_{p}\left(R_{e}\right)[(\pi D-R a)(L-2 b)] \frac{\left(\pi D N_{S}\right)^{2}}{2} \\
& F_{P}\left(R_{e}\right)=\frac{8}{R_{e}} \text { for } R_{e}<1000 \\
& \frac{1}{24.6} \mathrm{Re}^{-0.203} \text { for Re }>1000
\end{aligned}
$$

All other equations governing the design and performance of hydrostatic journal bearings are given elsewhere [1], and therefore need not to be repeated here.

Constraints

The following constraints are used
a. Eccentricity
$0<\frac{\varepsilon}{\varepsilon_{\text {max }}}<1.0$
b. Pressure ratio
$0<\beta<1.0$
c. Circumferential land width
$0<\bar{b}=\frac{b}{b_{\text {max }}}<1.0$

d. Circumferential width of axial land $0<\bar{a}=\frac{a}{a_{\max }} 1.0$

e. Bearing ciearance $0<\overline{\mathrm{C}}=\frac{\mathrm{C}}{\mathrm{C}_{\max }}<1.0$

\section{RESULTS AND DISCUSSION}

The optimization program was checked by solving a problem for which results were readily available [3,4]. The results are compared in table (1). In case one of the present results. the problem is optimized using the same constraints of references [3] and [4], while in case two the supply pressure was preselected to match the value of these published results, and all other constraints were left unchanged as in case one. In results is $9.39 \%$ less that the power losses of the present less than that of referen that of reference [3], and $9.32 \%$ ᄂ.. 
present work yields lower supply pressure. As the supply pressure was given a preselected value $[3,4]$ in case two, the optimum bearing length was reduced, while the minimum power losses remained below the published values. These results indicate that the present optimization method is capable to achieve better optimal designs.

Table (1): Comparison between the present results and the published results of refs. [3] and [4].

\begin{tabular}{|c|c|c|c|c|c|c|}
\hline \multirow[t]{2}{*}{$\begin{array}{l}\text { Design } \\
\text { Nariable }\end{array}$} & \multicolumn{2}{|c|}{ Constraints } & \multicolumn{2}{|c|}{$\begin{array}{l}\text { Published } \\
\text { results }[3,4]\end{array}$} & \multicolumn{2}{|c|}{ Present results } \\
\hline & Min & Max. & $\operatorname{Ref} .3$ & Ref. 4 & Case 1 & Case 2 \\
\hline$a / D$ & 0.1 & 0.166 & 0.1 & 0.103 & 0.1 & 0.1 \\
\hline $\mathrm{b} / \mathrm{L}$ & 0.05 & 0.1 & 0.05 & 0.05 & 0.051 & 0.0712 \\
\hline$\mu$ & 0.05 & 0.075 & 0.05 & 0.05 & 0.05 & 0.05 \\
\hline $\mathrm{L} / \mathrm{D}$ & 0.8 & 1.5 & 1.0 & 0.926 & 1.25 & 0.85 \\
\hline$\beta$ & 0.5 & 0.7 & 0.51 & 0.5 & 0.502 & 0.5 \\
\hline $\mathrm{Cx} 10^{4}$ & 0.15 & 0.25 & 0.15 & 0.15 & 0.15 & 0.25 \\
\hline $\mathrm{W}_{\mathrm{T}}$ & & & 56.31 & 56.76 & 51.47 & 51.6 \\
\hline $\mathrm{W} \times 10^{-4}$ & & & 0.588 & C. 588 & 0.6 & 0.488 \\
\hline $\mathrm{p}_{\mathrm{s}} \times 10^{-7}$ & & & 0.741 & 0.741 & 0.589 & $0.741^{\star}$ \\
\hline \multicolumn{7}{|c|}{${ }^{\star}$ preselected } \\
\hline$D=0.0$ & & $\mathrm{R}=4$ & & $\mathrm{~N}_{\mathrm{S}}=1$ & .5 & $=0.3$ \\
\hline
\end{tabular}

Bearing Clearance

Fig.l shows the variations of diensionless power losses with dimensionless bearing clearance for a square bearing at different supply pressures, while figure (2) shows a carpet plot for load variations at different aspect ratios (L/D). It is shown that for optimum designs, the power losses increases exponentially with bearing clearance. Bearings having large clearances require lower supply pressure at minimum power losses. On the contrary, precision bearings having small clearances would accept higher supply pressures as long as side leakage is considerably less and hence the pumping power is maintained at a reasonable level. Shorter bearings are also shown to result in high power losses due to side leakage effects.

In order to correlate the load capacity of fig.(2) with the associated power losses a carpet plot of the optimize configurations is made as shown in fig.(3). These results show that small bearing clearances are generally preferrable, though this may yield high manufacturing cost as a result of the associated high supply pressures. The variations of supply pressures with load cipacity and bearing clearances are deLmonstrated in fig.(4). It is also of interest to notice that, 


\begin{tabular}{|l|l|}
\hline$M D-9$ & 94 \\
\hline
\end{tabular}

$\Gamma$

precision beazings of optimized small clearances would generally be less sensitive to small variations in supply pressures.

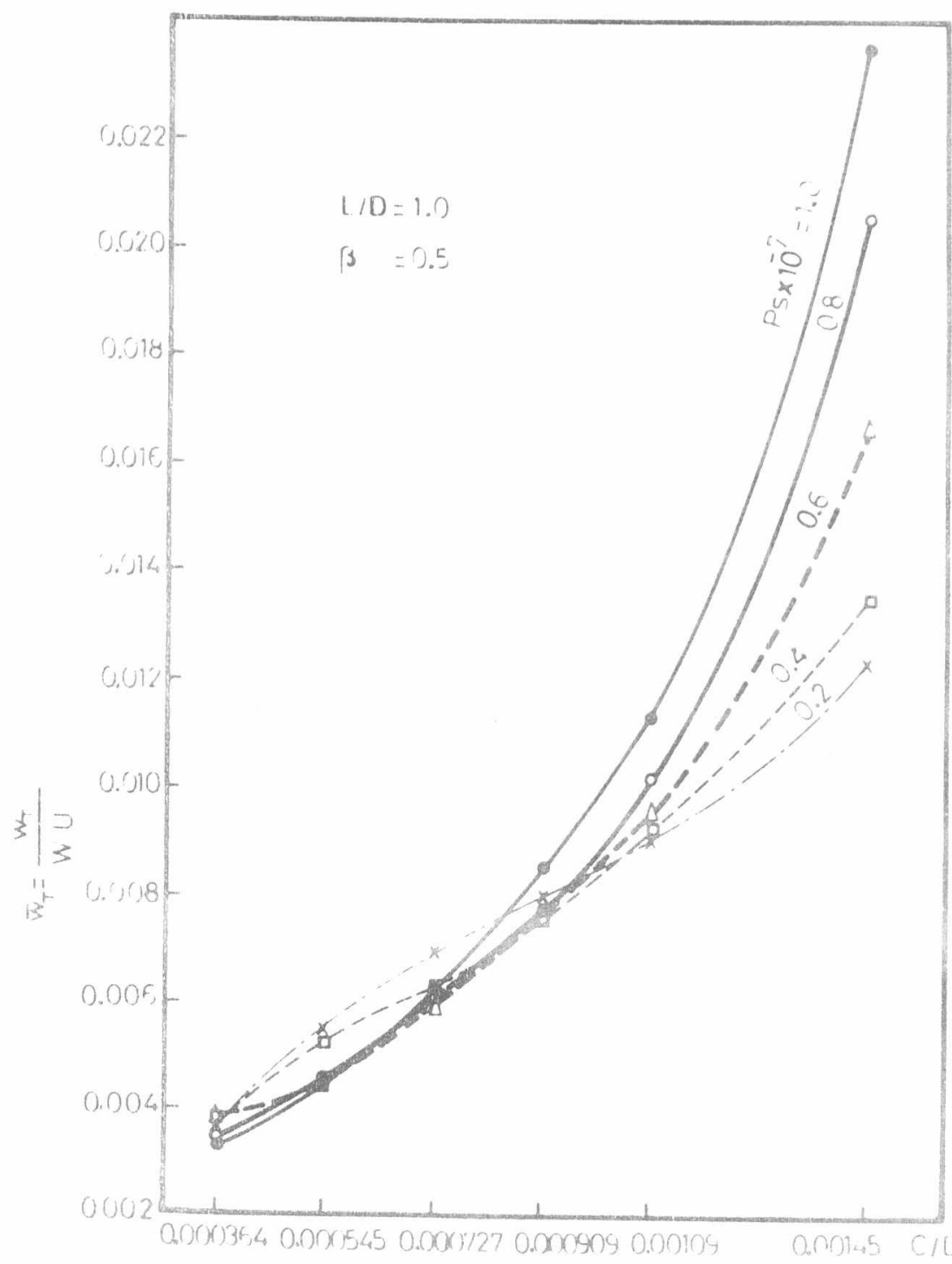

Fig(1) Variation of dimensionless tolal power lots $w_{T}$ with bearing clearance for different supply pressures.

Circumferential Land width.

Fig. (5) shows the variation of minimum power losses with land width at different bearing clearances, while fig. (6) shows the same variations at different supply pressures. These results shows that minimum power losses is achieved at smaller bearing clearances. For low supply pressures the optimum circumferential land width is much less than optimum values obtained at high supply pressures. This is due to the fact that wider circumferential lands considerably reduce the side leakage flow, particularly at high supply pressures and large L bearing clearances. Minimum side leakage obviously results 


\begin{tabular}{l|l}
\hline$M D-9$ & 95 \\
\hline
\end{tabular}
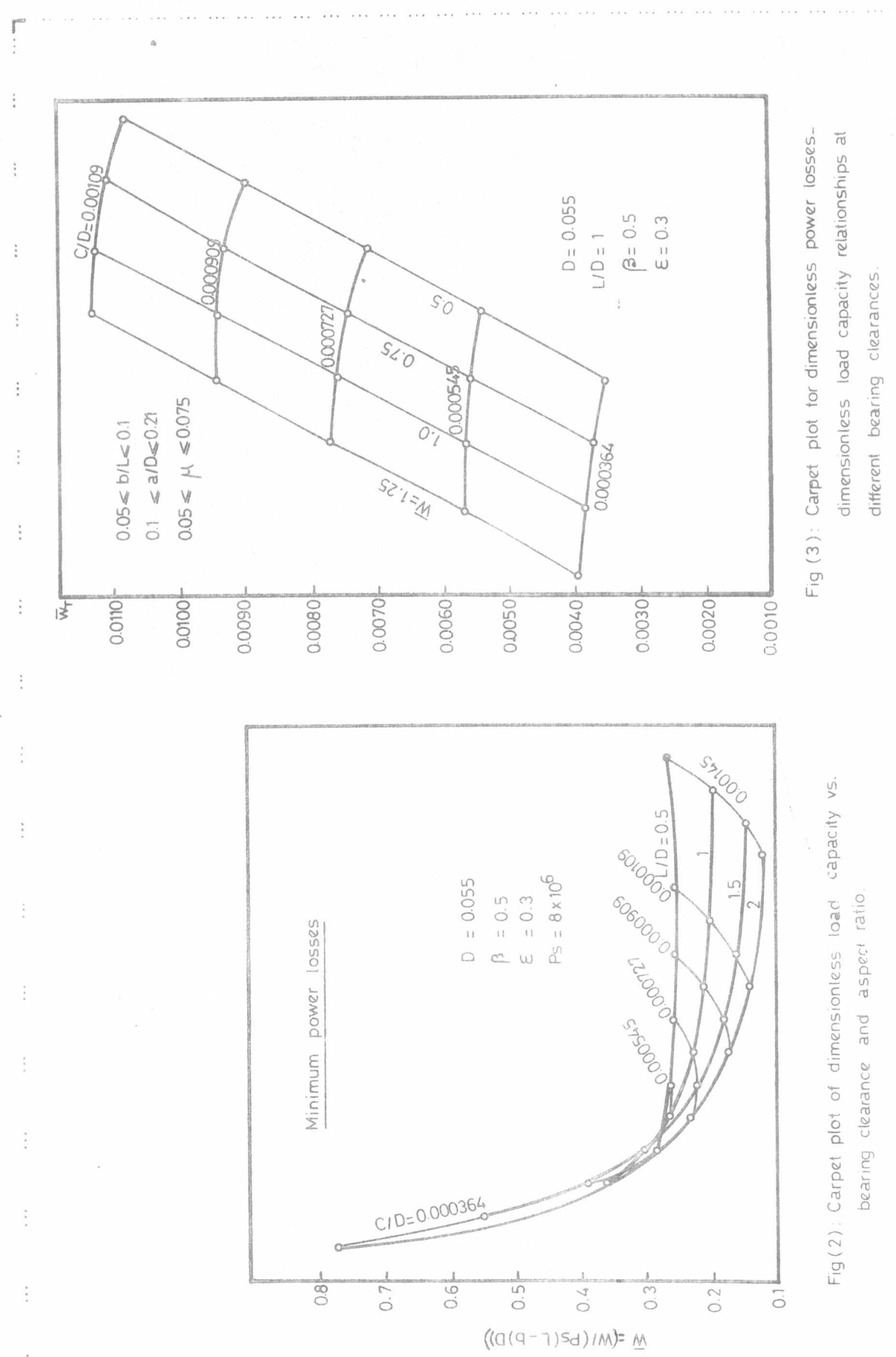


\begin{tabular}{|l|l|}
\hline MD-9 & 96 \\
\hline
\end{tabular}
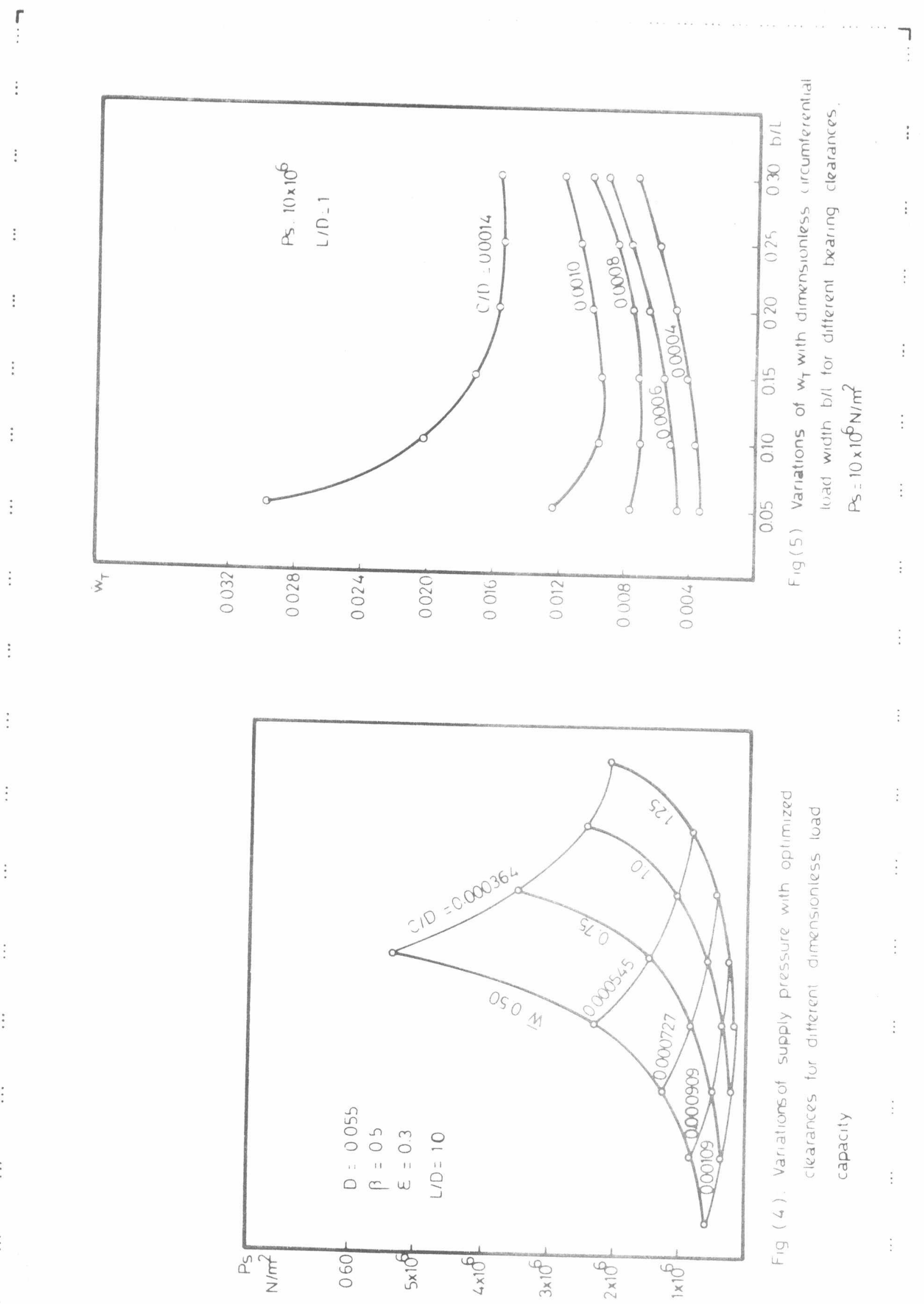

$i$ 

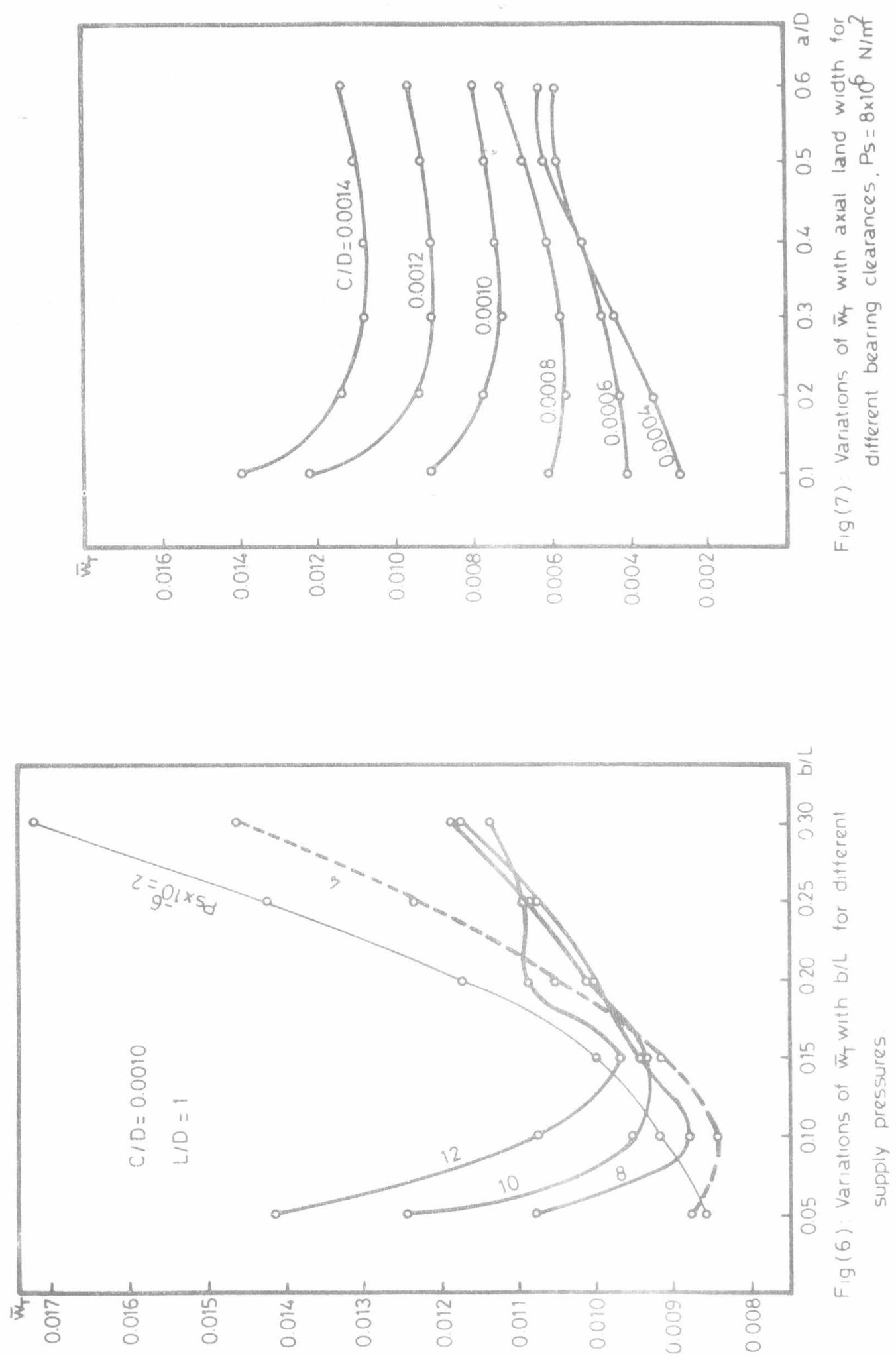


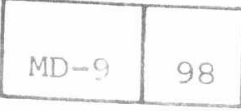

WIJUA A.M.E. CONFLRENCL

in leas oil flow and hence reduce the pumping power.

Jxial Land Width.

Fig. (7) shows the optimum axial land width's obtained at different bearing clearances. The power loss is shown to increase having smallcely with increasing axial land widths in bearings axial land clearances. It was therefore, found that the tend to take the lower limit of the constraints.

Oil Viscosity.

Fig. (8) shows the optimum values of oil viscosity for optimized bearings having different clearances. As the optimum ted and hence, more increases, less frictional losses are expec-

Area Ratio.

The optimum area ratio for the optimized configurations is given at different bearing clearances in fig. (9). These repromise between that an area ratio of 0.5 provides a good comdissipation.

Pressure Ratio.

The optimum pressure ratios obtained at different bearing clearances are shown in fig. (10), while the associated load capacities are shown in fig. (11). It was noted that the showing negligible considerably affect the pumping power, while area.

Some General Observations

In many optimum designs it was found that bearings having low performance characteristil clearances would result in a better speeds. Oil viscosity of the constraint in a con also found to take the upper limit optimum pressure ratio close terable number of designs. An mization results. An area ratio 0.5 was often found in optiresult in a good compromize betweet 0.5 was also found to power dissipation.

\section{CONCLUSIONS}

In designing externally pressurized bearings for minimum power losses, the design variables should be selected such that:

1. Clearance is an economically minimum

2. High supply pressures are avoided

4. Pressure ratio of 0.5 is a near ideal figure

high load of 0.5 is a good compromize between

L5. Viscous oils arey and low power losses 


\begin{tabular}{|l|l|}
\hline$M D-9$ & 99 \\
\hline
\end{tabular}
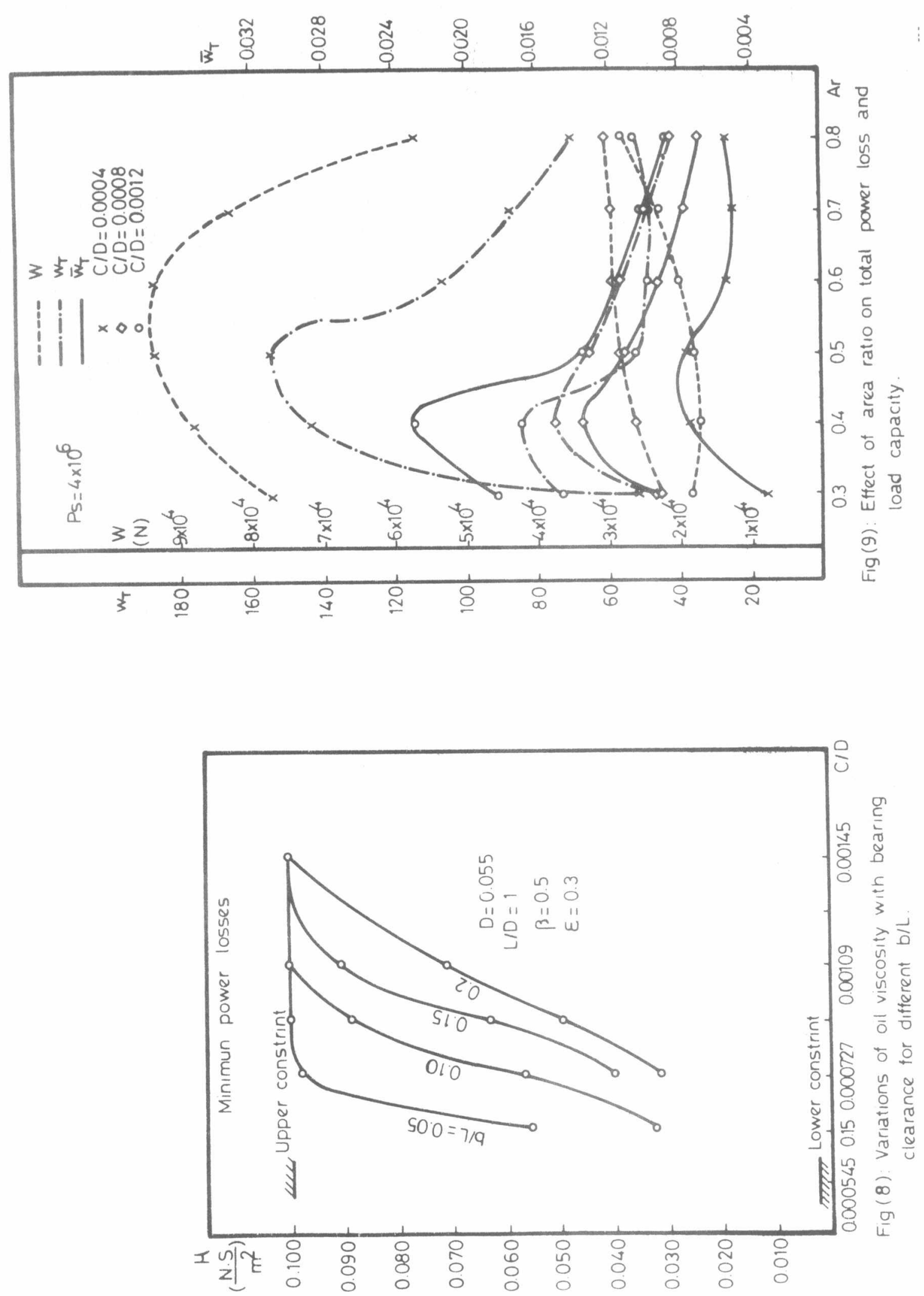
$r$
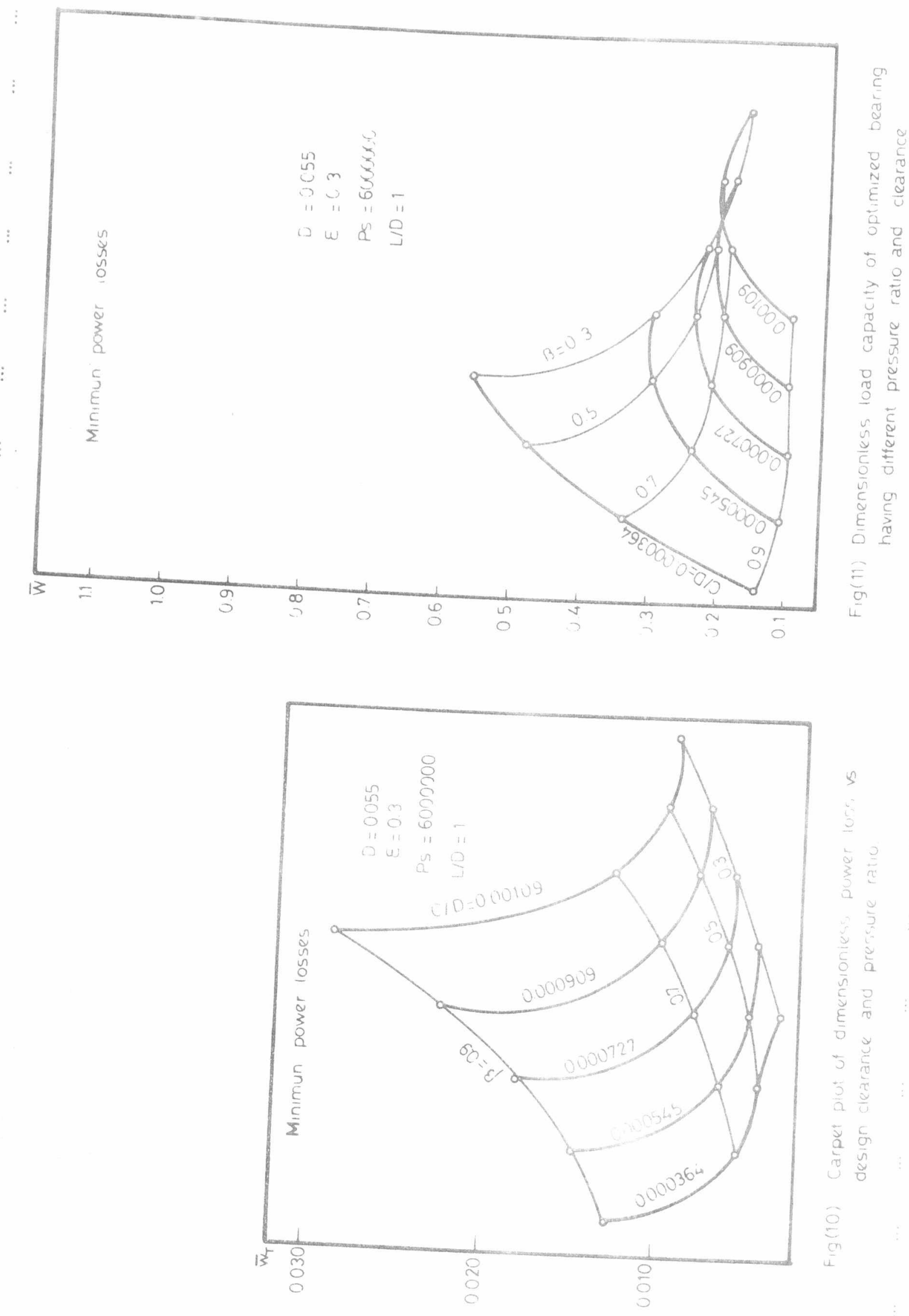

i. 


\section{REFEF INCES}

[1] El-hefnawy, N., "Optimum Design of Hydrostatic Journal. bearings", ..Sc. Thesis, Cairo University, Cairo, (1982).

[2] Hallstedt, G., "Standardized Hydrostatic Bearing Units," Joint Conf. on Externally Pressurized Bearings, Conventry U.K., pp. 422-430, (1971)。

[3] Sansinenea, J., and Bueno, R, "Computer Aided Design of Standardized Hydrostatic Journal Bearings," Proc of the 5 th Machine Tool Design and Research (MTDR) Conference Univ. of Birmingham, Birmingham, pp. 175-183, (1975).

[4] Bueno, R, "Diseno Y Optimizacion de cojinetes hidrostaticos radials. Publication INVEMA Lubrication hidrostatica III, pp. 84-99, ( 1972)

[5] Favoreto, M, "Optimization Methods for Hydrostatic Bearing Systems," The First World Meeting on Machine Tools, Milan, (1971).

[6] Cusano, C, and Conry, T, "Design of Multi-recess Hydrostatic Journal Bearings for Minimum Total Power Losses, Trans. ASME, J. of Engg. for Industry, 94,pp. 226-232, (1974)。

[7] Rowe, W., O'Donoghue, J. and Cameron, A, "Optimization of Externally Pressurized Bearings for Minimum Power and Low Temperature Rise," Tribology International, 12 pp. 153-157, (1970)。

[8] Moes, H, and Bosma, R, "Design Charts for Optimum Bearings Configurations," TRANS. ASME. J. Lub. Tech., 93, no.2, pp. 302-306, (1971).

[9] Bypan, L, Scibbe, B, and Anderson, W. "Optimization of Conical Hydrostatic Bearings for Minimum Friction," Trans. ASME, J. Lub. Tech., 94, no.2, pp. 136-142, (1972).

[10] Rosenbrock, H, "An Automatic Method for Finding the Greatest or Least Value of a Function," Computer Journal 3 . pp. 175-184, (1960).

\section{NOMENCLA'TURE}

Ar Ratio of total recess area to total bearing area $=\left(1-\frac{4 a}{\pi D}\right)\left(1-2 \frac{b}{L}\right)$

a circumferential length of axial land (1m)

b Axial length of circumferential land (mm)

C Diametral clearance (mm)

C Radial clearance (mm)

D Shaft diameter (mm)

e Eccentricity (mm)

L Axial length of bearing (mm)

$L_{r}$ Axial length of recess (mm) 


\begin{tabular}{l|l}
$M D-9$ & 102
\end{tabular}

$\Gamma$

$\mathrm{N}_{\mathrm{S}}$ Journal speed (rad/s)

$\mathrm{P}_{\mathrm{r}}$ Recess pressure $\left(\mathrm{N} / \mathrm{m}^{2}\right)$

$\mathrm{P}_{\mathrm{S}}$ Supply pressure $\left(\mathrm{N} / \mathrm{m}^{2}\right)$

Q Oil flow to bearing $\left(\mathrm{m}^{3} / \mathrm{s}\right)$

$R$ Number of recesses

Re Reynold's number

W Total load (N)

$\bar{W} \quad$ Dimensionless load $=W /\left[D(1-b) p_{S}\right]$

$W_{L}$ Frictional losses in land $(\mathrm{N} . \mathrm{m} / \mathrm{s})$

${ }^{w_{p}}$ Pumping power (N.m/s)

${ }^{w}$ Frictional losses in recess $(\mathrm{N} . \mathrm{m} / \mathrm{s})$

$\mathrm{W}_{\mathrm{T}}$ Total power (N.m/s)

B Pressure ratio $=\operatorname{Pr} / \mathrm{Ps}$

Pil density

$\mu \quad$ Dynamic viscosity

$\varepsilon \quad$ Eccentricity Ratio $=\mathrm{e} / \mathrm{c}$ 